\title{
Association between blood pressure measures and recurrent headache in adolescents: cross-sectional data from the HUNT-Youth study
}

\author{
Erling Tronvik • John-Anker Zwart • Knut Hagen • \\ Grete Dyb · Turid Lingaas Holmen · Lars Jacob Stovner
}

Received: 25 November 2010/ Accepted: 22 January 2011/Published online: 8 February 2011

(C) The Author(s) 2011. This article is published with open access at Springerlink.com

\begin{abstract}
The relationship between blood pressure and headache in youth has not been explored and the objective of the present study was to provide data on this association in an adolescent population. Cross-sectional data from a large population-based survey, the Young-HUNT study, on 5,847 adolescents were used to evaluate the association between blood pressure (systolic, diastolic, mean arterial and pulse pressure) and recurrent headache, including migraine and tension-type headache. Increasing pulse pressure was inversely related to recurrent headache prevalence, and both tension-type headache and migraine. For systolic blood pressure such an inverse relationship was present for recurrent headache and tension-type headache prevalence. For migraine, the results were not significant, although there was a tendency in the same
\end{abstract}

E. Tronvik $(\bowtie) \cdot$ J.-A. Zwart · K. Hagen - L. J. Stovner

Department of Neurology, Norwegian National

Headache Centre, Trondheim University Hospital,

7006 Trondheim, Norway

e-mail: Erling.Tronvik@ntnu.no

E. Tronvik · J.-A. Zwart · K. Hagen - L. J. Stovner Department of Neurosciences,

Norwegian University of Science and Technology,

7006 Trondheim, Norway

T. L. Holmen

Department of Public Health and General Practice, HUNT Research Centre, Norwegian University of Science and Technology, Trondheim, Norway

J.-A. Zwart

Department of Neurology, Ullevål University Hospital,

Oslo, Norway

J.-A. Zwart · G. Dyb

Faculty of Medicine, University of Oslo, Oslo, Norway direction $(p=0.05)$. High-pulse pressure has previously been found to be inversely related to the prevalence of migraine and tension-type headache in an adult population. This inverse relationship has now been demonstrated to be present among adolescents also, supporting the results from a previous study in adults, that blood pressure regulation may be linked to the pathophysiology of headache.

Keywords Headache Migraine $\cdot$ Blood pressure . Epidemiology $\cdot$ Adolescent

\section{Introduction}

A relationship between migraine and blood pressure (BP) has long been suspected, but the direction of the association has been controversial [1]. For many years, it was assumed that hypertension might be a cause of headache. Studies supporting this connection were published and the pulsatile characteristics of some headaches and the introduction of $\beta$-blockers in migraine prophylactic treatment may further have supported this view [2,3]. There is, however, a possibility that this observation may be an example of admission rate bias (Berkdon's bias) as hypertension and headache are common medical disorders and consulting the doctor for one of the disorders may give a higher likelihood of detecting the other condition. Later, epidemiological studies showing no relationship between headache and high-BP were published [4, 5], and in the International Classification of headache disorders II, it is stated that mildly or moderately elevated BP is not a cause of headache [6]. Recent epidemiological data in adult populations suggest even an inverse relationship between headache prevalence and both pulse pressure (PP), and systolic blood pressure (SBP) [7-10]. A little is known 
about this relation in the younger part of the population, in which, BP values normally are well within the normotensive range. Headache in adolescents is a frequent symptom [11], and the objective of this study was to explore the relation between BP and recurrent headache, including migraine or tension-type headache (TTH) in a large population-based study.

\section{Materials and methods}

The Nord-Trøndelag Health Study (HUNT) is one of the largest epidemiologic studies ever performed. NordTrøndelag County is located in the middle of Norway and is fairly representative of the population as a whole and the study is aimed at several large public health issues.

In 1995-1997, all students in junior high schools (aged 13-15 years) and high schools (aged 16-19 years), of the county of Nord-Trøndelag, were invited to participate in the youth part of the Nord-Trøndelag Health Study, the Young-HUNT study. A total of 8,984 students (88\%) out of 10,202 invited individuals completed a comprehensive self-administered questionnaire with different health-related items during one school hour. The study followed the school year instead of the calendar year. As adolescents usually graduate from high school, in the calendar year they become 19, about half of the 19-year olds had left school and were not invited. Accordingly, the 19-year-old students in the study population were excluded $(n=382)$. The few 12-year-old students in the first year of junior high were also excluded $(n=126)$. Questionnaires, where the headache question had not been answered $(n=221)$ were excluded, leaving a total study population of 8,255 (81\%). Within a month after completing the questionnaire, a clinical examination was performed in schools during school hours and included spirometry, weight, height and BP measurements. The intention was to let the whole population undergo a headache interview performed by trained nurses in connection with the clinical examination [12], but the interviews did not commence until February
1996 and this resulted in a lower number of interviewed individuals. Among the 5,847 adolescents 13-18 years of age that underwent the interview all had valid questionnaires and of these 5,832 had valid BP measurements. There was no major difference in sex and age distribution between the total questionnaire-based study population ( $n=8,255$ ) and the questionnaire-based population that also were interviewed ( $n=5,847)$ [12]. The first question of the interview was whether the students had experienced recurring headaches not related to cold, fever or any other type of illness, and whether they had experienced such headaches during the last 12 months. The students were then asked to classify their headache(s) according to two descriptions [13], one for migraine and the other for TTH (see "Appendix"). These descriptions were based on the International Headache Society (IHS) criteria [14] with the exceptions that the number of attacks and the duration of headaches were not included [15]. The students were also given a third option (non-classifiable headache), in case none of the two descriptions resembled their symptoms. Headache frequency was also registered, and they were asked to indicate the average number of days they had experienced headaches in the past year; less than one day per month (less than monthly), 1-3 days per month (monthly), 1-5 days per week (weekly), more than 5 days per week (daily). The "recognition-based" headache diagnosis obtained by the nurses has been validated previously against extensive semi-structured interviews by neurologists [15]. The positive predictive value for migraine was $89 \%$ and the negative predictive value $90 \%$. For TTH, the positive and negative predictive values were 83 and $91 \%$, respectively. The one-year prevalence of migraine was $7 \%$, of TTH $18 \%$ and of non-classifiable headache $4.8 \%$. Headache at the time of investigation was not registered. Background data on demographics and headache diagnostic groups and frequency are given in Tables 1, 2 and 3. For more detailed information, see Ref. [12].

Blood pressure is a measure of the force applied to the wall of the arteries as the heart pumps blood through

Table 1 Study population

\begin{tabular}{|c|c|c|c|c|c|c|c|}
\hline \multirow[t]{2}{*}{ Schools } & \multirow[t]{2}{*}{$\begin{array}{l}\text { Number invited } \\
\text { (aged } 12-19 \text { years) }\end{array}$} & \multicolumn{3}{|c|}{$\begin{array}{l}\text { Participants with valid questionnaires } \\
\text { (aged } 13-18 \text { years) }\end{array}$} & \multicolumn{3}{|c|}{$\begin{array}{l}\text { Participants included with valid questionnaires, } \\
\text { interviews and blood pressure data (aged } 13-18 \text { years) }\end{array}$} \\
\hline & & $n$ & Mean age (SD) & $\%$ Girls & $n$ & Mean age (SD) & $\%$ Girls \\
\hline Junior high school & 5,004 & 4,508 & $14.6(0.9)$ & 50.5 & 3,265 & $14.7(0.9)$ & 51.0 \\
\hline High school & 4,913 & 3,733 & $17.4(0.9)$ & 49.2 & 2,555 & $17.5(0.9)$ & 52.9 \\
\hline 'Not in school' & 285 & 14 & $17.2(0.9)$ & 64.3 & 12 & $17.2(0.9)$ & 75.0 \\
\hline Total & 10,202 & 8,255 & $15.9(1.7)$ & 49.9 & 5,832 & $5.9(1.6)$ & 51.9 \\
\hline
\end{tabular}

$S D$ standard deviation

See Ref. [12] for more detailed information 
Table 2 The prevalence of overall recurrent headache, and subgroups migraine, tension-type headache, and non-classifiable headache

\begin{tabular}{lclll}
\hline & $\begin{array}{c}\text { Overall recurrent } \\
\text { headache }(\%)\end{array}$ & Migraine $(\%)$ & $\begin{array}{l}\text { Tension-type } \\
\text { headache }(\%)\end{array}$ & $\begin{array}{l}\text { Non-classifiable } \\
\text { headache }(\%)\end{array}$ \\
\hline Boys $n=2,801$ & $581(20.7)$ & $115(4.1)$ & $330(11.8)$ & $117(4.2)$ \\
Girls $n=3,031$ & $1,091(36.0)$ & $226(7.5)$ & $652(21.5)$ & $163(5.4)$ \\
\hline
\end{tabular}

Sixty-nine participants had co-occurrence of migraine and tension-type headache and these were excluded from the migraine and tension-type headache groups

Table 3 Recurrent headache frequency

\begin{tabular}{llllr}
\hline & $\begin{array}{l}<1 \text { day per } \\
\text { month }(\%)\end{array}$ & $\begin{array}{l}1-3 \text { days per } \\
\text { month }(\%)\end{array}$ & $\begin{array}{l}1-5 \text { days per } \\
\text { week }(\%)\end{array}$ & $\begin{array}{l}>5 \text { days per } \\
\text { week }(\%)\end{array}$ \\
\hline Boys $n=2,801$ & $147(5.2)$ & $279(10.0)$ & $112(4.0)$ & $5(0.2)$ \\
Girls $n=3,031$ & $174(5.7)$ & $542(17.9)$ & $329(10.9)$ & $24(0.8)$ \\
\hline
\end{tabular}

the body. The pressure is determined by the force and amount of blood pumped and the size and flexibility of the arteries, and is usually represented by two values. The systolic arterial pressure is defined as the peak pressure in the arteries, which occurs at the beginning of the cardiac cycle. The diastolic arterial pressure is the lowest pressure which is present in the resting phase of the cardiac cycle. BP is also characterized by its pulsatile and steady components. The pulsatile component, estimated by PP (SBP-DBP), represents BP variation during the cardiac cycle and is affected by left ventricular ejection fraction, arterial stiffness, early pulse wave reduction and heart rate. The steady component, estimated by MAP, is a function of left ventricular contractility, heart rate and vascular resistance and elasticity averaged over time [16].

BP was measured with the adolescent sitting [17]. First, the upper arm circumference was measured to the closest centimeter. If the circumference was less than $24 \mathrm{~cm}$, a small cuff was used, if it was between 24 and $34 \mathrm{~cm}$ a medium cuff was used, and if it was $35 \mathrm{~cm}$ or more, a large cuff was used. The measurements were done using an automatic oscillometric technique (507 N monitor, Criticare System Inc., USA). The adolescents rested for $2 \mathrm{~min}$ before the first measurement, and the second and third measurements were done with $1 \mathrm{~min}$ intervals. Blood pressure was measured manually when an automatic recording could not be obtained. The mean value of the last two measurements was used in the analyses.

Ethics

A written consent from the parents was required for students younger than 16 years of age. The Young-HUNT study was approved by the Regional committee for ethics in medical research, and by the Norwegian data inspectorate.

Statistical analysis

The prevalence odds ratio (OR) for the association between recurrent headache (including subgroups migraine and TTH) and different BP groups was estimated using multiple logistic regression. In order to establish uniform groups, subjects with two or more recurring headaches (i.e., cooccurring migraine and TTH) were omitted from the analyses. The term "recurrent headache" in this paper refers to the headache variable obtained during the interview and includes subjects with migraine, TTH and nonclassifiable headache, while "headache" is used as a more general and unspecific term. SBP, diastolic blood pressure (DBP), mean arterial pressure (MAP) and PP were each divided into six categories using the 10, 25, 50, 75 and 90\% in the cross-sectional data. Potential confounding was evaluated by adjusting for age and weight. As the results were not affected when weight was added as covariates to the model, this variable was omitted. Due to several statistical calculations, the level of significance was set at $p<0.001$. A two-sided trend test was performed to evaluate the probability of a linear relationship between BP categories and headache prevalence. To further assess deviation from the linearity assumption, a trend test for BP as a continuous variable was performed for the different headache categories, in which, the trend test for BP as a categorical variable had shown significance. As a continuous variable the $p$ value ranged from $p=0.002$ to $p<0.0001$. Spearman's correlation coefficient $\left(r_{\mathrm{s}}\right)$ was used to investigate the relationship between headache frequency and BP categories. Statistical analyses were 
performed using SPSS version 14.0 for Windows (SPSS Inc., Chicago, USA).

\section{Results}

Systolic and diastolic blood pressure

There was a linear trend of decreasing prevalence of overall recurrent headache (Fig. 1) and TTH ( $p$ trend value $<0.001$ ) with increasing SBP values analyzing boys and girls together. For migrainous headache the same tendency was observed, but the finding was not significant $(p=0.05)$.

For DBP, there was no association with the prevalence of overall recurrent headache ( $p$ trend value is 0.36), migraine ( $p$ trend value is 0.19 ) or TTH ( $p$ trend value is 0.64).

When stratifying for sex and diagnostic group, the results were not significant (data not shown).

Pulse pressure and mean arterial pressure

In boys and girls, combined analyses revealed a highly significant inverse relationship between increasing PP and recurrent headache (Fig. 1), and for migraine ( $p$ trend value $<0.001$ ) and TTH ( $p$ trend value $<0.0001)$. Stratifying for sex and diagnostic group, this inverse relationship was not significant (data not shown).

PP increases with age in the general population. To evaluate the influence of age on the relationship between
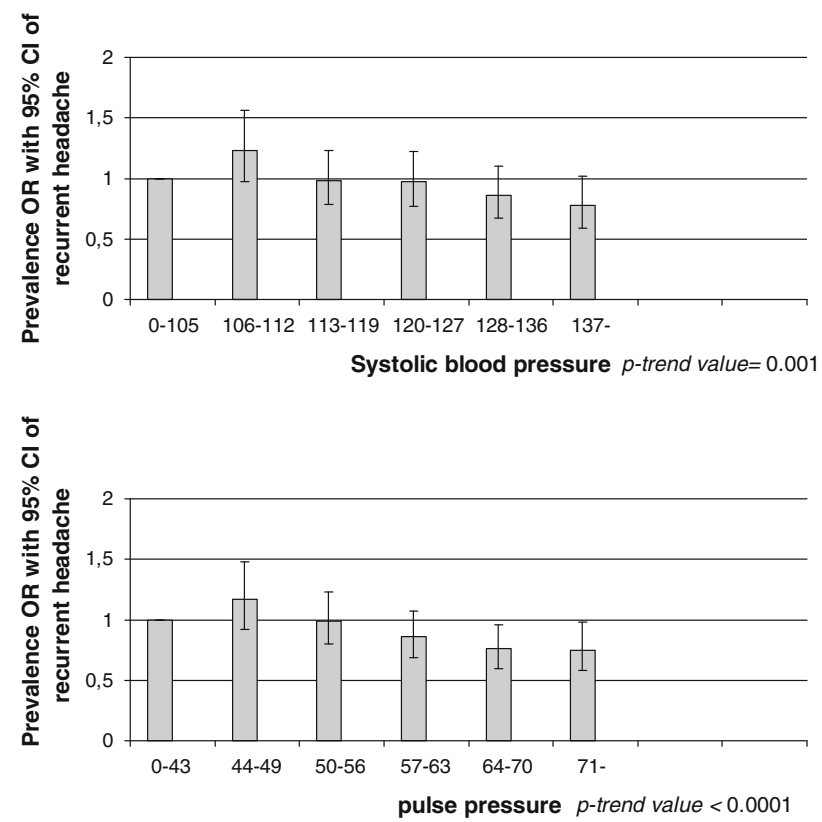

Fig. 1 The relation between blood pressure and recurrent headache in both genders combined (ORs with 95\% CIs, $n=5,832$ )
PP and headache prevalence, we split the data in two, using the median PP value as cut-off, and plotted the prevalence of migraine and TTH versus age (Fig. 2). In both the migraine and the TTH group, there was a tendency for high-PP to be associated with a lower prevalence of headache, but this was not significant.

Mean arterial pressure was not associated with the prevalence of recurrent headache ( $p$ trend value is 0.37 ), migraine ( $p$ trend value is 0.78 ) or TTH ( $p$ trend value is 0.07 ) in the combined analyses or the analyses stratified by gender and diagnostic group (data not shown).

Blood pressure and headache frequency

Recurrent headache frequency for both genders combined was categorized into four different groups; less than one day per month (less than monthly), 1-3 days per month (monthly), 1-5 days per week (weekly), more than 5 days per week (daily). There was a weak negative correlation between recurrent headache frequency and $\mathrm{PP}\left(r_{\mathrm{s}}=\right.$ $-0.06, p<0.001)$. For SBP, DBP and MAP, no significant association with recurrent headache frequency was observed.

Blood pressure and use of pain-relieving medication

To determine whether the level of BP influenced use of pain-relieving medication, use of common analgesics and migraine-specific medication for both genders combined were subclassified into three categories each; never used, periodic use and almost daily use. A weak negative association was present between the use of migraine-specific medication and PP $\left(r_{\mathrm{s}}=-0.06, p<0.001\right)$. For SBP, DBP and MAP, no significant association with use of migraine-specific medication was found. Use of common analgesics showed a weak negative association with

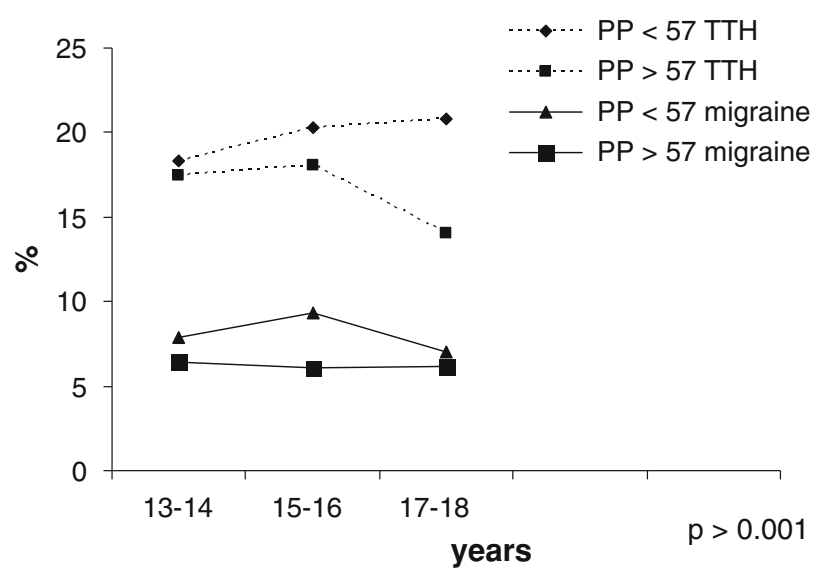

Fig. 2 The prevalence of tension-type headache (TTH) and migraine in groups with pulse pressure (PP) above or below the median related to age (both genders) 
PP $\quad\left(r_{\mathrm{s}}=-0.07, p<0.001\right)$ and $\mathrm{SBP} \quad\left(r_{\mathrm{s}}=-0.06\right.$, $p<0.001)$. For DBP and MAP, no significant association was observed.

\section{Discussion}

This is a population-based study to investigate a possible association between BP and headache prevalence among adolescents, testing for linear trends. The main finding was the inverse relationship between PP and recurrent headache prevalence, including the subgroups TTH and migraine for boys and girls combined.

The relationship between recurrent headache frequency and PP was weak, but the negative association is the one which would be expected from the direction of the associations between headache prevalence and the $\mathrm{BP}$ variables.

Similarly, the fact that use of migraine-specific medication and common analgesics was lower in those with higher PP and supports the main finding of a negative association between PP and recurrent headache.

Results from this adolescent population is in accordance with data from an adult population from the HUNT study, in which high-systolic and high-pulse pressure were associated with less migraine and non-migrainous headache [7]. Similar results have been published by other groups $[8-10$, $18,19]$. The inverse relationship is not restricted to headache, but seems to be valid for pain in other parts of the body as well [20]. The findings seem to be more consistent for headache in general than for migraine [7], and the present study demonstrates that this inverse relationship is present even in adolescents, who in general are normotensive.

We have previously argued that [7], most likely, this inverse relationship between BP and headache prevalence is the result of a phenomenon called hypertension associated hypalgesia [21, 22]. There is evidence that a higher level of BP may inhibit pain transmission through stimulation of the baroreflex system, possibly due to an interaction between nociceptive and cardiovascular centers in the brainstem [22]. This phenomenon is also present within the normotensive range [21], a fact that is in accordance with the results presented in this study.

Strengths of the study are the large and unselected population and the use of validated diagnoses. A limitation of this study is that only cross-sectional data are available. Another limitation is that the results did not remain significant with stratification for gender, and as there was no interaction by gender, this was probably due to lack of power. The relatively narrow range of BP-values in an adolescent population may also explain the need for a large number of subjects in the analyses.
The high participation rate in the questionnaire-based part of the study indicates that the study cohort represents the population fairy well, and that no serious selection bias was present. It also seems reasonable to assume that the prevalence rates of recurrent headaches based on data from the interviewed population are fairly representative. There were no systematic selection of subjects and no major differences in age and sex distribution between the total questionnaire-based study population and questionnairebased study population that also were interviewed [12]. There is probably a little or no interest-related selection bias, since headache and BP were only a few among many other objects of the study. A total of $4.8 \%$ of the interviewed population reported their headache not to be consistent with either migraine or TTH and were categorized as non-classifiable headache. Others have reported higher rates of non-classifiable headaches among adolescents $[23,24]$, and the applicability of the IHS criteria in the pediatric population has been debated. The recognitionbased technique has been validated but may underestimate the occurrence of more than one headache, thus those with migraine may not report also having TTH [15]. A large proportion of non-recurrent headaches, however, are probably secondary headache disorders related to cold, fever or other diseases, or they may be very rare primary headache attacks [25]. In the present study, 77\% reported having had headache, but only $29 \%$ reported recurrent headaches [12]. In one Danish study as many as $60-70 \%$ of the adolescents had infrequent TTH [26], thus one cannot exclude that subjects with sporadic primary headaches in the present study were included in the reference group and might accordingly weaken and underestimate the associations observed. The prevalence of migraine and TTH are, however, in accordance with the previous studies [27, 28]. Differences in methodology and screening question accounts for a substantial part of the various prevalence rates reported [28, 29], but a robust approach assessing comorbidity is to include only those that suffer from headaches [30].

Why are these results important? Several of the prophylactic medications used for treating migraine headache today are antihypertensive agents and the reason for their effect is not known. Nociceptive and blood pressure regulatory centers in the brain stem lie anatomically close in proximity and it has also been demonstrated that the neurons of pain regulatory centres (periaqueductal gray and rostral ventrolateral medulla) may be excited by pharmacologically induced changes in BP [31, 32].

Further research into the relationship between headache and BP may give valuable information on pathophysiological mechanisms involved in headache/migraine, general pain-modulating mechanisms and mode of action of antihypertensive drugs used for migraine prophylaxis. 
Acknowledgments The Youth part of Nord-Trøndelag Health Study (The Young-HUNT Study) is collaboration between HUNT Research Centre, Faculty of Medicine, The Norwegian University of Science and Technology (NTNU, Verdal), Norwegian Institute of Public Health, and Nord-Trøndelag County Council.

\section{Conflict of interest None.}

Open Access This article is distributed under the terms of the Creative Commons Attribution License which permits any use, distribution and reproduction in any medium, provided the original author(s) and source are credited.

\section{Appendix: headache description used in headache interviews}

Alternative 1 (migraine) This headache often comes in attacks, the pain is moderate or severe, and may start on one side of the head. The headaches are pounding or pulsating, and I prefer not to move my head. I am often nauseated and may vomit. When I have this headache light or sounds bother me.

Alternative 2 (tension-type headache) This headache may start gradually and the pain is mild or moderate. The pain is usually located in the whole head, or in the neck. It feels tightening or pressing (like a band around the head). I usually have no nausea or vomiting. When I have this headache I can normally keep on with my schoolwork, homework and normal physical activity.

Alternative 3 (non-classifiable headache) Neither alternative 1 or 2 describes my headache.

\section{References}

1. Agostoni E, Aliprandi A (2008) Migraine and hypertension. Neurol Sci 29(Suppl 1):S37-S39. doi:10.1007/s10072-0080883-8

2. Walker CH (1959) Migraine and its relationship to hypertension. Br Med J 2(5164):1430-1433

3. Badran RH, Weir RJ, McGuiness JB (1970) Hypertension and headache. Scott Med J 15(2):48-51

4. Buring JE, Hebert P, Romero J, Kittross A, Cook N, Manson J, Peto R, Hennekens C (1995) Migraine and subsequent risk of stroke in the physicians' health study. Arch Neurol 52(2):129_ 134

5. Rasmussen BK, Olesen J (1992) Symptomatic and nonsymptomatic headaches in a general population. Neurology 42(6): 1225-1231

6. Headache Classification Subcommittee of the International Headache S (2004) The international classification of headache disorders. 2nd edn, Cephalalgia 24 (Suppl 24):1-160

7. Tronvik E, Stovner LJ, Hagen K, Holmen J, Zwart JA (2008) High pulse pressure protects against headache: prospective and cross-sectional data (HUNT study). Neurology 70(16):1329-1336

8. Tzourio C, Gagniere B, El Amrani M, Alperovitch A, Bousser MG (2003) Relationship between migraine, blood pressure and carotid thickness. A population-based study in the elderly. Cephalalgia 23(9):914-920

9. Gudmundsson LS, Thorgeirsson G, Sigfusson N, Sigvaldason H, Johannsson M (2006) Migraine patients have lower systolic but higher diastolic blood pressure compared with controls in a population-based study of 21,537 subjects. The Reykjavik study. Cephalalgia 26(4):436-444

10. Hagen K, Stovner LJ, Vatten L, Holmen J, Zwart JA, Bovim G (2002) Blood pressure and risk of headache: a prospective study of 22,685 adults in Norway. J Neurol Neurosurg Psychiatry 72(4):463-466

11. Kernick D, Reinhold D (2008) Children and adolescents with headache: what do they need? J Headache Pain doi:10.1007/ s10194-008-0042-x

12. Zwart JA, Dyb G, Holmen TL, Stovner LJ, Sand T (2004) The prevalence of migraine and tension-type headaches among adolescents in Norway. The Nord-Trondelag Health Study (HeadHUNT-Youth), a large population-based epidemiological study. Cephalalgia 24(5):373-379

13. Dyb G, Holmen TL, Zwart JA (2006) Analgesic overuse among adolescents with headache: the Head-HUNT-Youth Study. Neurology 66(2):198-201

14. Headache Classification Commitee of the International Headache Society (1988) Classification and diagnostic criteria for headache disorders, cranial neuralgia and facial pain. Cephalalgia 8 (suppl 7):1-96

15. Zwart JA, Dyb G, Stovner LJ, Sand T, Holmen TL (2003) The validity of 'recognition-based' headache diagnoses in adolescents. Data from the Nord-Trondelag Health Study 1995-1997, Head-HUNT-Youth. Cephalalgia 23(3):223-229

16. Sesso HD, Stampfer MJ, Rosner B, Hennekens CH, Gaziano JM, Manson JE, Glynn RJ (2000) Systolic and diastolic blood pressure, pulse pressure, and mean arterial pressure as predictors of cardiovascular disease risk in men. Hypertension 36(5):801-807

17. Fasting MH, Nilsen TI, Holmen TL, Vik T (2008) Life style related to blood pressure and body weight in adolescence: cross sectional data from the Young-HUNT study, Norway. BMC Public Health 8:111. doi:10.1186/1471-2458-8-111

18. Wiehe M, Fuchs SC, Moreira LB, Moraes RS, Fuchs FD (2002) Migraine is more frequent in individuals with optimal and normal blood pressure: a population-based study. J Hypertens 20(7): 1303-1306

19. Fuchs FD, Gus M, Moreira LB, Moreira WD, Goncalves SC, Nunes G (2003) Headache is not more frequent among patients with moderate to severe hypertension. J Hum Hypertens 17(11):787-790

20. Hagen K, Zwart JA, Holmen J, Svebak S, Bovim G, Stovner LJ (2005) Does hypertension protect against chronic musculoskeletal complaints? The Nord-Trondelag Health Study. Arch Intern Med 165(8):916-922

21. Ghione S (1996) Hypertension-associated hypalgesia. Evidence in experimental animals and humans, pathophysiological mechanisms, and potential clinical consequences. Hypertension 28(3): 494-504

22. Guasti L, Zanotta D, Mainardi LT, Petrozzino MR, Grimoldi P, Garganico D, Diolisi A, Gaudio G, Klersy C, Grandi AM, Simoni C, Cerutti S (2002) Hypertension-related hypoalgesia, autonomic function and spontaneous baroreflex sensitivity. Auton Neurosci 99(2): 127-133

23. Fendrich K, Vennemann M, Pfaffenrath V, Evers S, May A, Berger K, Hoffmann W (2007) Headache prevalence among adolescents-the German DMKG headache study. Cephalalgia 27(4):347-354. doi:101111/j1468-2982200701289x

24. Kroner-Herwig B, Heinrich M, Morris L (2007) Headache in German children and adolescents: a population-based epidemiological study. Cephalalgia 27(6):519-527. doi:101111/j1468-29 $82200701319 x$ 
25. van der Wouden JC, van der Pas P, Bruijnzeels MA, Brienen JA, van Suijlekom-Smit LW (1999) Headache in children in Dutch general practice. Cephalalgia 19(3):147-150

26. Russell MB, Levi N, Saltyte-Benth J, Fenger K (2006) Tensiontype headache in adolescents and adults: a population based study of 33, 764 twins. Eur J Epidemiol 21(2):153-160. doi: 10.1007/s10654-005-6031-3

27. Anttila P (2006) Tension-type headache in childhood and adolescence. Lancet Neurol 5(3):268-274

28. Stovner LJ, Zwart JA, Hagen K, Terwindt G, Pascual J (2006) Epidemiology of headache in Europe. Eur J Neurol 13(4): 333-345

29. Hagen K, Zwart JA, Aamodt AH, Nilsen KB, Brathen G, Helde G, Stjern M, Tronvik EA, Stovner LJ (2008) A face-to-face interview of participants in HUNT 3: the impact of the screening question on headache prevalence. J Headache Pain 9(5):289-294. doi:10.1007/s10194-008-0062-6

30. Hagen K, Stovner L, Zwart JA (2007) Potentials and pitfalls in analytical headache epidemiological studies-lessons to be learned from the Head-HUNT Study. Cephalalgia 27(5):403-413

31. Dworkin BR, Filewich RJ, Miller NE, Craigmyle N, Pickering TG (1979) Baroreceptor activation reduces reactivity to noxious stimulation: implications for hypertension. Science 205(4412): 1299-1301

32. Murphy AZ, Ennis M, Rizvi TA, Behbehani MM, Shipley MT (1995) Fos expression induced by changes in arterial pressure is localized in distinct, longitudinally organized columns of neurons in the rat midbrain periaqueductal gray. $\mathbf{J}$ Comp Neurol 360(2):286-300 